\title{
EDITORIAL
}

\section{Benefits and risks of the P/F approach}

\author{
L. Gattinoni* ${ }^{*}$, F. Vassalli and F. Romitti
}

๑ 2018 Springer-Verlag GmbH Germany, part of Springer Nature and ESICM

\section{Introduction}

The $\mathrm{PaO}_{2} / \mathrm{FIO}_{2}$ ratio represents the pressure exerted in the blood by the unbound molecules of oxygen, normalized to the fractional volume of inspired oxygen. The $\mathrm{PaO}_{2} / \mathrm{FIO}_{2}$ ratio is used to assess the lung's capability to oxygenate the blood, primarily in ARDS, where its thresholds of 150, 200, and 300 are used/proposed to classify ARDS severity $[1,2]$. Ideally, a given $\mathrm{PaO}_{2} / \mathrm{FIO}_{2}$ ratio value should correspond to a definite lung severity, independently of $\mathrm{FIO}_{2}$. In reality, the same severity may be associated with quite different $\mathrm{PaO}_{2} / \mathrm{FIO}_{2}$ values, depending on several factors, as previously described [3].

\section{Alveolar $\mathrm{PO}_{2}$}

Ideally, $\mathrm{PaO}_{2}$ should be normalized to alveolar $\mathrm{PO}_{2}$ $\left(\mathrm{PAO}_{2}\right)$ instead of $\mathrm{FIO}_{2}$. Indeed, for the same $\mathrm{PaO}_{2} /$ $\mathrm{FIO}_{2}$ ratio, the $\mathrm{PaO}_{2} / \mathrm{PAO}_{2}$ ratio may vary depending on barometric pressure $(\mathrm{Pb}), \mathrm{PaCO}_{2}$, and the respiratory exchange ratio $(R)$, as may be easily understood by examining the alveolar air equation:

$$
\mathrm{PAO}_{2}=\mathrm{FIO}_{2} \times(\mathrm{Pb}-47)-\frac{\mathrm{PaCO}_{2}}{R}
$$

Consequently, an identical $\mathrm{PaO}_{2} / \mathrm{FIO}_{2}$ ratio of 150 measured at the barometric pressure of Mexico City $(2250 \mathrm{~m})$ or Göttingen $(150 \mathrm{~m})$ in two patients breathing $30 \% \mathrm{O}_{2}$, with identical $\mathrm{PaCO}_{2} / R$ ratios, would result in a sharply different $\mathrm{PaO}_{2} / \mathrm{PAO}_{2}$ ratios: 0.32 in Göttingen, decidedly less than the 0.49 in Mexico. The impact of $\mathrm{PaCO}_{2} / R$ ratio on $\mathrm{PAO}_{2}$ is less dramatic, unless extracorporeal $\mathrm{CO}_{2}$ removal is in use. In this case, the $R$ may be very low, producing a consistent decrease in the alveolar $\mathrm{PO}_{2}$, if $\mathrm{FIO}_{2}$ is not adequately increased [4-6].

\footnotetext{
*Correspondence: gattinoniluciano@gmail.com Department of Anesthesiology, Emergency and Intensive Care Medicine, University of Göttingen (UMG), Robert-Koch-Straße 40, 37075 Göttingen, Germany
}

\section{Arterial $\mathrm{PO}_{2}$}

According to Riley's model (two compartment lung, one ideally perfused and ventilated, one perfused and not ventilated) [7], the arterial oxygen content $\left(\mathrm{CaO}_{2}\right)$ is the weighted mean of the oxygen contents blended from the two compartments. The blood from the perfused/ventilated compartment will have a $\mathrm{PO}_{2}$ equal to the alveolar $\mathrm{PAO}_{2}$ in equilibrium with the capillary oxygen content $\left(\mathrm{CcO}_{2}\right)$, while the blood coming from the perfused/nonventilated compartment will have a $\mathrm{PO}_{2}$ and oxygen content equal to the mixed venous blood $\left(\mathrm{CvO}_{2}\right)$. The fraction of the cardiac output coming from the perfused/ non-ventilated compartment (venous admixture) may be easily quantitated at the bedside:

$$
\text { Venous admixture }=\frac{\mathrm{CcO}_{2}-\mathrm{CaO}_{2}}{\mathrm{CcO}_{2}-\mathrm{CvO}_{2}} .
$$

Although venous admixture is the variable that more accurately assesses oxygenation impairment, it nowadays is considered impractical and cumbersome; hence, the $\mathrm{PaO}_{2} / \mathrm{FIO}_{2}$ is used for severity assessment. The limits of the $\mathrm{PaO}_{2} / \mathrm{FIO}_{2}$ approach can be understood by considering Eq. 1 (which defines the $\mathrm{PAO}_{2}$ ) together with Eq. 2 (which defines the venous admixture). Indeed,

1. $\mathrm{CcO}_{2}$ strictly depends on $\mathrm{PAO}_{2}$, which is proportional to the $\mathrm{FIO}_{2}$ (Eq. 1), while the $\mathrm{CaO}_{2}$ is proportional to the $\mathrm{PaO}_{2}$ (through the oxygen dissociation curve) [8]. Therefore, the difference $\left(\mathrm{CcO}_{2}-\mathrm{CaO}_{2}\right)$ and the ratio $\left(\mathrm{CaO}_{2} / \mathrm{CcO}_{2}\right)$ are strictly related and hold the same physiological meaning of $\mathrm{PaO}_{2} / \mathrm{FIO}_{2}$ ratio.

2. Because the $\left(\mathrm{CcO}_{2}-\mathrm{CaO}_{2}\right)$ difference equals the product: [venous admixture $\times\left(\mathrm{CcO}_{2}-\mathrm{CvO}_{2}\right)$ ], the same $\left(\mathrm{CcO}_{2}-\mathrm{CaO}_{2}\right)$, i.e., the same $\mathrm{PaO}_{2} / \mathrm{FIO}_{2}$, may derive from myriad combinations of venous admixture fraction and $\left(\mathrm{CcO}_{2}-\mathrm{CvO}_{2}\right)$. These range from

\section{Springer}


extremely high venous admixture fraction and low $\left(\mathrm{CcO}_{2}-\mathrm{CvO}_{2}\right)$, i.e., high $\mathrm{CvO}_{2}$, or vice versa.

3. $\mathrm{CcO}_{2}$ primarily depends on $\mathrm{FIO}_{2}$; therefore, for a given $\mathrm{FIO}_{2}$ any change of $\left(\mathrm{CcO}_{2}-\mathrm{CvO}_{2}\right)$ only depends upon the $\mathrm{CvO}_{2}$.

4. $\mathrm{CvO}_{2}$, for a given arterial oxygenation, strictly depends on oxygen consumption $\left(\mathrm{VO}_{2}\right)$ and cardiac output (Qt); indeed, $\mathrm{CvO}_{2}=\mathrm{CaO}_{2}-\mathrm{VO}_{2} / \mathrm{Qt}$.

The consequence of these relationships are summarized in Fig. 1. Figure 1a shows $\mathrm{PaO}_{2}$ as a function of $\mathrm{FIO}_{2}$ at venous admixture levels from $10 \%$ to $40 \%$, and a cardiac output range between 6 and $10 \mathrm{~L} / \mathrm{min}$, assuming an oxygen consumption of $200 \mathrm{ml} / \mathrm{min}$. Two features are worth noting:

- $\mathrm{PaO}_{2}$ is lower at higher venous admixture levels and increases non-linearly with $\mathrm{FIO}_{2}$ along the isovenous admixture lines.

- For a given oxygen consumption and venous admixture level, cardiac output exerts a tremendous effect on $\mathrm{PaO}_{2}$. It must be stressed, however, that the primary determinant is the $\mathrm{CvO}_{2}$ (see point 4 above).

Figure $1 \mathrm{~b}$ presents the $\mathrm{PaO}_{2} / \mathrm{FIO}_{2}$ ratio as a function of $\mathrm{FIO}_{2}$ at venous admixture levels between $10 \%$ and $40 \%$ over a cardiac output range between $6 \mathrm{~L} / \mathrm{min}$ (lover $\mathrm{CvO}_{2}$ ) and $10 \mathrm{~L} / \mathrm{min}$ (higher $\mathrm{CvO}_{2}$ ). This figure underlines the limits of $\mathrm{PaO}_{2} / \mathrm{FIO}_{2}$ alone in the assessment of lung injury severity. As an example, at venous admixture $20 \%$ and $10 \mathrm{~L} / \mathrm{min}$ of cardiac output, the $\mathrm{PaO}_{2} / \mathrm{FIO}_{2}$ always exceeds 300 , i.e., no ARDS. However, for the same venous admixture $(20 \%)$ with a lower cardiac output of $6 \mathrm{~L} / \mathrm{min}$, a given patient would be classified as "mild ARDS" across $\mathrm{FIO}_{2}$ values from 0.3 to 0.7 but classified as "no ARDS" at $\mathrm{FIO}_{2}$ values from 0.7 to 1.0. Another hypothetical patient at venous admixture of $30 \%$, depending on $\mathrm{FIO}_{2}$ and cardiac output, may oscillate between no ARDS, mild ARDS, or moderate-severe ARDS.

\section{Clinical use}

\section{Assessment of severity}

Although the $\mathrm{PaO}_{2} / \mathrm{FIO}_{2}$ ratio has limits as a surrogate of venous admixture, the $\mathrm{PaO}_{2} / \mathrm{FIO}_{2}$ ratio offers several advantages: first, it is easy to measure; second, when tested across large populations (but not necessarily in individual patients), the $\mathrm{PaO}_{2} / \mathrm{FIO}_{2}$ reflects reasonably well the severity of anatomical derangements measured by $\mathrm{CT}$ scanning [1]. Nonetheless, the accuracy of $\mathrm{PaO}_{2} / \mathrm{FIO}_{2}$ ratio for indexing ARDS severity (e.g., Berlin ARDS definition) would improve greatly if determined at a standard PEEP value. In previous work [10], we used $5 \mathrm{cmH}_{2} \mathrm{O}$ to avoid the masking effect of higher PEEP on $\mathrm{PaO}_{2} / \mathrm{FIO}_{2}$ ratio, which may be due either to decreasing venous admixture or altering hemodynamics. Standardization of $\mathrm{FIO}_{2}$ would further improve the accuracy and comparability of severity among patients [11].

\section{PEEP selection}

Changes in $\mathrm{PaO}_{2} / \mathrm{FIO}_{2}$ ratio are frequently used to assess recruitability during ARDS, on the assumption that increases in $\mathrm{PaO}_{2} / \mathrm{FIO}_{2}$ ratio are due to lung recruitment [12]. Unfortunately, increasing PEEP often decreases cardiac output. Theoretically, if the venous admixture and

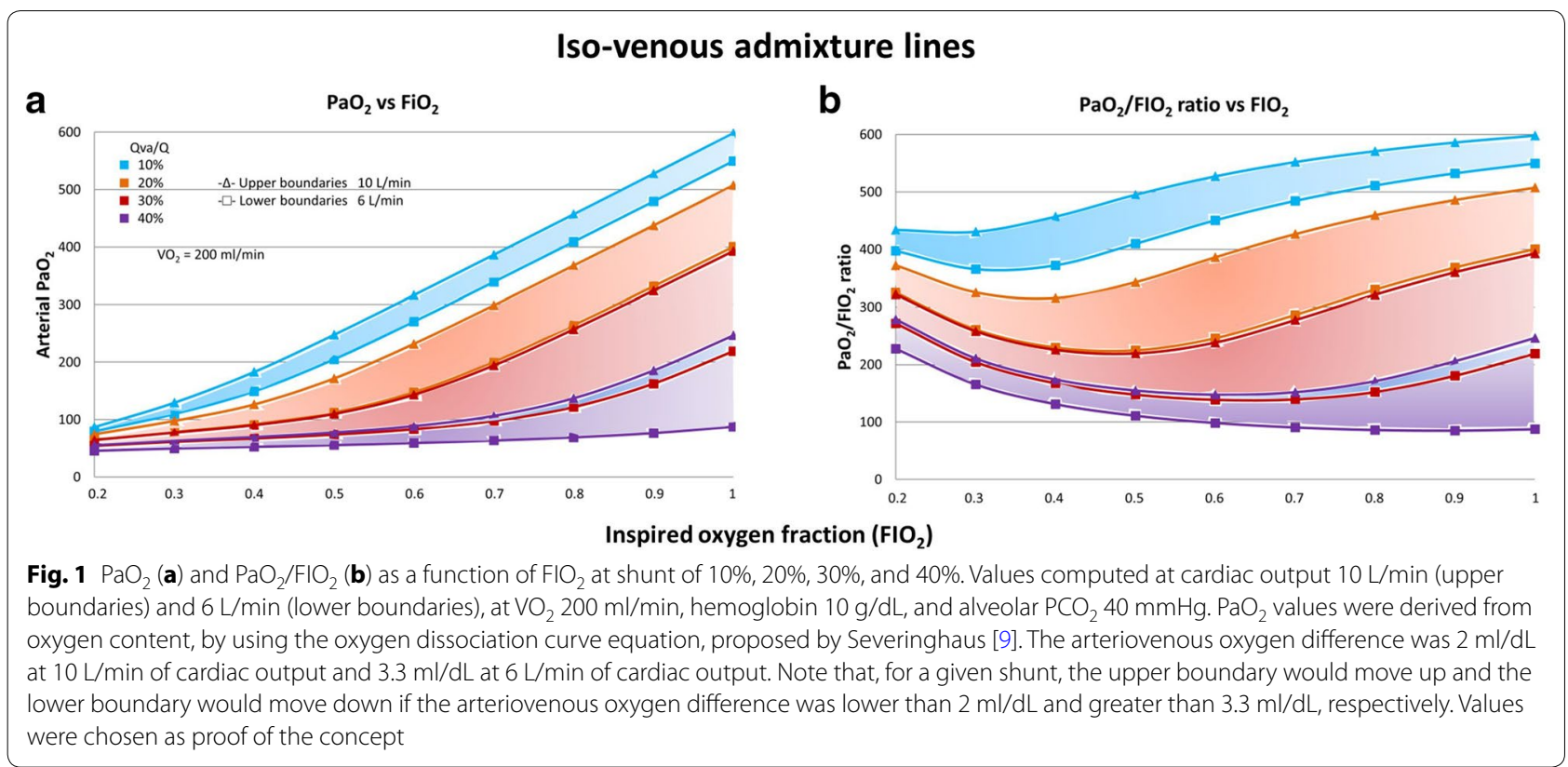


oxygen consumption do not change, this would reduce the $\mathrm{PaO}_{2} / \mathrm{FIO}_{2}$ ratio. However, this seldom occurs, as the venous admixture usually changes in proportion to the cardiac output [12-15]. Therefore, caution must be used when setting PEEP with the $\mathrm{PaO}_{2} / \mathrm{FIO}_{2}$ approach, as its apparent that improvement may be due to decreased cardiac output in the absence of recruitment-a principle long known but often forgotten.

\section{Conclusions}

- $\mathrm{PaO}_{2} / \mathrm{FIO}_{2}$ ratio is a surrogate of venous admixture measurement for approximating ARDS severity and relates well to anatomical differences on the $\mathrm{CT}$ scan.

- At a given venous admixture, the $\mathrm{PaO}_{2} / \mathrm{FIO}_{2}$ ratio may differ, depending on oxygen consumption and cardiac output. Conversely, for the same $\mathrm{PaO}_{2} / \mathrm{FIO}_{2}$, venous admixture may vary with $\mathrm{FIO}_{2}$.

- To better assess severity of lung injury and follow its evolution, $\mathrm{PaO}_{2} / \mathrm{FIO}_{2}$ ratio should be measured at standardized levels of PEEP and $\mathrm{FIO}_{2}$. Selecting PEEP according to $\mathrm{PaO}_{2} / \mathrm{FIO}_{2}$ ratio may be misleading if hemodynamics are not taken into account.

\section{Compliance with ethical standards}

\section{Conflicts of interest}

On behalf of all authors, the corresponding author states that there is no conflict of interest.

Received: 26 September 2018 Accepted: 10 October 2018

Published online: 23 October 2018

\section{References}

1. ARDS Definition Task Force, Ranieri VM, Rubenfeld GD, Thompson BT, Ferguson ND, Caldwell E, Fan E, Camporota L, Slutsky AS (2012) Acute respiratory distress syndrome: the Berlin definition. JAMA 307:2526-2533
2. Maiolo G, Collino F, Vasques F, Rapetti F, Tonetti T, Romitti F, Cressoni M, Chiumello D, Moerer O, Herrmann P, Friede T, Quintel M, Gattinoni L (2018) Reclassifying acute respiratory distress syndrome. Am J Respir Crit Care Med. https://doi.org/10.1164/rccm.201709-18040C

3. Aboab J, Louis $\mathrm{B}$, Jonson B, Brochard L (2006) Relation between $\mathrm{PaO}_{2}$ / $\mathrm{FIO}_{2}$ ratio and $\mathrm{FIO}_{2}$ : a mathematical description. Intensive Care Med 32:1494-1497

4. Kolobow T, Gattinoni L, Tomlinson T, Pierce JE (1978) An alternative to breathing. J Thorac cardiovascr Surg 75:261-266

5. Gattinoni L, Kolobow T, Tomlinson T, White D, Pierce J (1978) Control of intermittent positive pressure breathing (IPPB) by extracorporeal removal of carbon dioxide. Br J Anaesth 50:753-758

6. Gattinoni L (2016) Ultra-protective ventilation and hypoxemia. Crit Care 20:130

7. Riley RL, Cournand A (1949) Ideal alveolar air and the analysis of ventilation-perfusion relationships in the lungs. J Appl Physiol 1:825-847

8. Gabel RA (1980) Algorithms for calculating and correcting blood-gas and acid-base variables. Respir Physiol 42:211-232

9. Severinghaus JW (1979) Simple, accurate equations for human blood $\mathrm{O}_{2}$ dissociation computations. J Appl Physiol Respir Environ Exerc Physiol 46:599-602

10. Caironi $\mathrm{P}$, Carlesso E, Cressoni M, Chiumello D, Moerer O, Chiurazzi C, Brioni M, Bottino N, Lazzerini M, Bugedo G, Quintel M, Ranieri VM, Gattinoni L (2015) Lung recruitability is better estimated according to the Berlin definition of acute respiratory distress syndrome at standard $5 \mathrm{~cm}$ $\mathrm{H}_{2} \mathrm{O}$ rather than higher positive end-expiratory pressure: a retrospective cohort study. Crit Care Med 43:781-790

11. Allardet-Servent J, Forel JM, Roch A, Guervilly C, Chiche L, Castanier M, Embriaco N, Gainnier M, Papazian L (2009) $\mathrm{FIO}_{2}$ and acute respiratory distress syndrome definition during lung protective ventilation. Crit Care Med 37(202-207):e204-206

12. Lemaire F, Harf A, Simonneau G, Matamis D, Rivara D, Atlan G (1981) Gas exchange, static pressure-volume curve and positive-pressure ventilation at the end of expiration. Study of 16 cases of acute respiratory insufficiency in adults. Ann Anesthesiol Fr 22:435-441

13. Freden F, Cigarini I, Mannting F, Hagberg A, Lemaire F, Hedenstierna $G$ (1993) Dependence of shunt on cardiac output in unilobar oleic acid edema. Distribution of ventilation and perfusion. Intensive Care Med 19:185-190

14. Dantzker DR, Lynch JP, Weg JG (1980) Depression of cardiac output is a mechanism of shunt reduction in the therapy of acute respiratory failure. Chest 77:636-642

15. Lynch JP, Mhyre JG, Dantzker DR (1979) Influence of cardiac output on intrapulmonary shunt. J Appl Physiol Respir Environ Exerc Physiol 46:315-321 